\title{
Exploration and exploitation within and across intra-organisational domains and their reactions to firm-level failure
}

\author{
Peiran Su and Peter McNamara* \\ UCD Michael Smurfit Graduate Business School, Blackrock, Co. Dublin, Ireland
}

\begin{abstract}
This study examines the evolution of exploration and exploitation within intra-organisational domains, specifically, the technological and market knowledge domains in high-technology firms. It simultaneously tests the interaction between exploration and exploitation across domains. Furthermore, this paper examines the impact of firm-level failure experience on exploration and exploitation within each domain. Based on longitudinal analysis of crossnational panel data on drug development initiatives obtained from 191 biopharmaceutical firms from 1990 to 2008, we find a negative relationship between firms' innovation experience and exploration orientation within domains. Technological exploration and market exploration are competing with each other. We further find that failure experience stimulates technological search but not market search. This work contributes to the exploration and exploitation literature by extending domain separation to the internal context of an organisation theoretically and empirically. It further contributes by using performance feedback theory to explore the impact of failure on exploration and exploitation.
\end{abstract}

Keywords: exploration exploitation; failure experience; domain separation; technological domain; market domain; research and development; pharmaceuticals; clinical trials

\section{Introduction}

Balancing exploration and exploitation has been the core of the strategic renewal of the firm. Researchers have identified four modes of balancing exploration and exploitation, namely, contextual ambidexterity (Gibson and Birkinshaw 2004), organisational separation (He and Wong 2004), temporal separation (Tushman and Anderson 1986) and domain separation (Lavie and Rosenkopf 2006) (please refer to Lavie, Stettner, and Tushman (2010) and Simsek et al. (2009) for a comprehensive review). Domain separation suggests that 'organisations specialise in either exploration or exploitation in particular organisational domains while balancing these activities across domains', which serves for 'relaxing inconsistencies and trade-offs between exploration and exploitation' (Lavie, Stettner, and Tushman 2010, 129). 
Research on domain separation of exploration and exploitation has been scarce and mostly limited to the inter-organisational context, such as alliances (Lavie and Rosenkopf 2006). Little effort has been made to investigate the domain separation of exploration and exploitation in the internal context of an organisation, such as in relation to new product development. The present study fills this gap by identifying two internal domains of an organisation, technological knowledge and market knowledge, based on the innovation and new product development literatures. It hypothesises and tests the relationship between exploration and exploitation within and across intra-organisational domains and, hence, answers the first research question of this study: how do exploration and exploitation evolve within and interact across the domains in the internal context of an organisation? The answer will shed light on balancing exploration and exploitation across intra-organisational domains and encourage the use of the domain separation approach of exploration and exploitation.

This study also examines the impact of firm-level failure on the evolution of exploration and exploitation within the internal domains of the firm. According to performance feedback theory (Greve 1998), performance is a major explanatory variable in most models of organisational learning (Cyert and March 1963; Levinthal and March 1981). Performance above or below an aspiration level is often considered to be an indicator of success or failure. Students of performance feedback theory have generally argued for a positive relationship between failure and subsequent exploration activities. Organisations that performed poorly are more likely to reorient than organisations that experienced success (Fombrun and Ginsberg 1990; Ginsberg 1988). The former respond to poor performance by making a broad range of strategic and operational changes (Audia and Greve 2006; Bolton 1993; Greve 2003).

In contrast, other researchers show that firms are generally risk-adverse and, hence, failure reduces exploration. Failure reduces resources that are available in firms (March 1991) and generates cognitive constraints (Shepherd 2003; Shepherd, Covin, and Kuratko 2009), which forces firms to search less external knowledge and repeatedly utilise existing knowledge to generate confidence, reliability and efficiency. Little empirical effort has been made to examine the relationship between failure and tendencies for exploration and exploitation. Authors focusing on learning from success and failure often display a strong tendency to focus on success and to under-sample failure (Levinthal and March 1993). Recently, scholars have shown an interest in distinguishing the effects of failure from those of success on subsequent organisational performance (Baum and Dahlin 2007). An emerging research stream has focused on learning from failure (Homsma et al. 2009; Kim and Miner 2007; McGrath 1999; Minniti and Bygrave 2001; Shepherd 2003; Sitkin 1992). It is on this basis that this study asks its second research question: how does failure affect firms' exploration and exploitation orientations within their internal domains? By answering this question, the present article simultaneously examines the failure trap notion (Levinthal and March 1993).

This paper is one of few which aim to extend the domain separation of exploration and exploitation by identifying and developing domains in the internal context of an organisation. It delineates distinct domains of exploration and exploitation within the boundary of the firm. It contributes significantly to the progress and researchers' understanding of the domain separation approach to balancing exploration and exploitation by advancing the notion that firms may not balance exploration and exploitation within domains but may, rather, achieve balance across domains. We also contribute to the literature by combining organisational learning literature and performance feedback theory to examine the impact of firm-level failure on tendencies towards exploration and exploitation within the domains. 


\section{Theory and hypotheses}

\subsection{Exploration and exploitation}

Exploration includes 'things captured by terms such as search, variation, risk taking, experimentation, play, flexibility, discovery, innovation' and exploitation includes such 'things as refinement, choice, production, efficiency, selection, implementation, execution' (March 1991, 71). Levinthal and March (1993) defined exploration as 'the pursuit of new knowledge, of things that might come to be known' and exploitation as 'the use and development of things already known' (104). The essence of exploration is experimentation with new alternatives, while the essence of exploitation is the refinement and extension of existing competences. Whereas exploration employs varied and dispersed knowledge in new ways, exploitation leverages existing knowledge in well-understood ways (Rosenkopf and Nerkar 2001; Taylor and Greve 2006; Vassolo, Anand, and Folta 2004; Vermeulen and Barkema 2001). Firms focusing on exploration tend to pursue more knowledge that is new to the firms now than they did in the past. Firms focusing on exploitation act in a reverse fashion, pursuing less knowledge that is new to the firms now than they did in the past.

\subsection{Domain separation approach}

Domain separation (Lavie and Rosenkopf 2006) argues that organisations can focus on exploration or exploitation within particular domains. The balance between the two can be carried out in multiple domains of an organisation. 'As organisations strive toward balance, they do not need to reconcile exploration and exploitation within each domain, as long as an overall balance is maintained across domains .... The main advantage of domain separation relative to organisational separation and temporal separation is that it enables organisations to avoid the inherent trade-offs that emerge when seeking to balance exploration and exploitation within a given domain' (Lavie, Stettner, and Tushman 2010, 134-35). For instance, Lavie and Rosenkopf (2006) identified three domains of exploration and exploitation in alliance formation, depending on whether an alliance was a knowledge-generating or knowledge-leveraging one (i.e. function domain), whether the partner had prior ties to the firm (i.e. structure domain) and whether the partner's organisational attributes differed from those of prior partners (i.e. attribute domain).

\subsection{Technological and market knowledge domains}

We identify two domains of exploration and exploitation in new product development, depending on the type of knowledge involved in new product development. The two domains in the internal context of the firm are technological knowledge and market knowledge. Technological and market knowledge have been distinguished in various studies (Kogut and Zander 1992; Shane 2000; Song et al. 2005). Recently, Lichtenthaler (2009) identified them as two critical components of prior knowledge within organisations. Building on both Cohen and Levinthal's (1990) and Tsai's (2001) work, Lichtenthaler (2009) noted that 'technological knowledge is the knowledge that a firm actually explores, transforms, and exploits in its absorptive capacity processes' (823). Lichtenthaler (2009) suggested that 'market knowledge ... refers to applications and commercialisation opportunities for technological knowledge' (823), building upon studies by Teece's (2007) and Van den Bosch, Volberda, and De Boer (1999).

The importance of the two domains has been widely utilised in the product innovation literature (Dougherty 1992). Technological and market knowledge are critical sources of sustainable 
competitive advantage that firms use to leverage their assets and achieve superior performance (Helfat and Peteraf 2003). The foundations of successful organisations lie in their ability to be productive at research and development, to introduce new products, to adopt best practice and to deliver quality products and services (Teece 2007). It is thus critical for firms to search technological opportunities while simultaneously learning about customer needs in order to have more commercialisation opportunities. Managers must thus assess how technologies will evolve and how and when competitors, suppliers and customers will respond to this (Teece 2007). This requires specific knowledge so that user needs can also be understood (Nonaka and Toyama 2007). It is unlikely for new products to be successful if the new technology does not meet customer needs. Echoing this point, studies in the marketing literature have emphasised the interaction between marketing on the one hand and research and development on the other (Gupta, Raj, and Wilemon 1986; Li and Calantone 1998; Song and Dyer 1995; Song and Parry 1997).

\subsection{Exploration and exploitation within domains}

Exploration and exploitation require different mindsets and organisational routines. They are competing for scarce resources within a domain and, hence, will be mutually exclusive (Gupta, Smith, and Shalley 2006). Exploration and exploitation are interdependent and should be conceptualised as two ends of a continuum within a domain. The distinction between the two is often 'a matter of degree rather than kind' (Lavie, Stettner, and Tushman 2010, 114). Exploration and exploitation thus include at their cores the degree of being 'new' (Gupta, Tesluk, and Taylor 2007; Tushman and Moore 1982). Gupta, Tesluk, and Taylor (2007) noted that 'most new ideas emerge as novel recombination of old ideas. Restricting the definition of innovation only to those ideas that are utterly new to the world would make this concept almost empty and devoid of any connection with ground-level reality.' Therefore, exploration and exploitation need to be specific to a particular domain. In this study, exploration and exploitation in the domain of technological knowledge are associated with the extent to which a firm utilises technology that is 'new to the firm'. Exploration and exploitation in the market knowledge domain refers to the extent to which acquired knowledge about markets and customer needs is new to the firm.

Lavie and Rosenkopf (2006) studied exploration and exploitation in inter-organisational domains, such as function, structure and attribute in an alliance formation. Their study disclosed a self-reinforcing trend in the evolution of exploration and exploitation within each domain. For example, in the structure domain, experience of structure exploration led to stronger exploration in that domain. Lavie and Rosenkopf (2006) argued for two mechanisms, absorptive capacity and organisational inertia, that underlay the evolution of exploration orientation. Absorptive capacity, which refers to 'the ability of a firm to recognise the value of new, external information, assimilate it, and apply it to commercial ends' (Cohen and Levinthal 1990, 128), facilitates exploration. Organisational inertia triggers exploitation. It refers to 'typical rates of change' that correspond with the organisation's responses to the occurrence of threats and opportunities in its environment (Hannan and Freeman 1984, 151). Organisations exhibit inertia when they adhere to current routines and resist change. The mechanisms for exploration and exploitation within domains obtain in this study. Absorptive capacity and organisational inertia apply to search of technological and market knowledge.

This study further complements the theoretical mechanisms by providing two latent mediating constructs to strengthen its argument. The first is the homophily principle (McPherson, SmithLovin, and Cook 2001), which suggests that the social networks of individuals in an organisation 
reinforce their communication and affect the information they receive, the attitudes they form, the interactions they experience and the values they share. Homophily intensifies the homogeneity of knowledge involved in the organisation and limits the individuals' cognitive processes and the breadth of their knowledge base. Thus, the scope of search for solutions is constrained by their limited knowledge base. The second mechanism is structural independence between exploration and exploitation in an organisation. Exploration requires a different set of capabilities from exploitation (Nonaka and Takeuchi 1995) because exploration contains more diversified knowledge, less attention to organisational routines, more uncertainty and higher risk (Benner 2002; March 1991). The two latent mechanisms support a reinforcing tendency for exploration and exploitation within domains. Furthermore, because of the strong tendency towards either exploration or exploitation (Levinthal and March 1993) as well as the concern for the survival of the organisations, Beckman (2006) found that experienced top management teams favoured exploitation over exploration. As knowledge accumulates within organisations, the refinement of existing knowledge is more efficient than experimenting with new knowledge. Accumulated knowledge improves technological and market bases in the organisations, which consequently makes exploration more difficult and less attractive.

Hypothesis 1a. Within the technological knowledge domain, there is a negative relationship between innovation experience and exploration.

Hypothesis 1b. Within the market knowledge domain, there is a negative relationship between innovation experience and exploration.

\subsection{Exploration and exploitation across domains}

Across domains, exploration and exploitation will be generally orthogonal. Thus, 'high levels of exploration or exploitation in one domain may coexist with high levels of exploration or exploitation in the other domain' (Gupta, Smith, and Shalley 2006, 697). Since balancing exploration and exploitation within domains is challenging, the present work argues that firms may avoid the inefficiencies which emerge from the trade-offs within domains by pursuing balance across domains. However, unlike in cases which involve exploring in one domain and exploiting in the other, simultaneously exploring or exploring across the domains may entail undesirable difficulties. High levels of exploitation in both the technological and the market knowledge domains may cause the firms to be locked out of the market (March 1991; Schilling 1998). They may face technological constraints and lose market opportunities by focusing on the refinement of existing knowledge. High levels of exploration in both domains may also involve high levels of uncertainty and risk, which are less favoured by organisations who may have a preference for short-term results. Therefore, exploitation in technological knowledge and exploration in market knowledge or exploration in technological knowledge and exploitation in market knowledge tend to be more valued choices of new product development.

It has been argued that new product development might create one type of knowledge and leverage another (Danneels 2002). Some who conceive of exploration as technological research and development activities and exploitation as marketing-related activities in a larger scope (Voss, Sirdeshmukh, and Voss 2008) have suggested that the interaction between technological and market knowledge is asymmetric (Levinthal and March 1993). The two compete for scarce resources and follow an orthogonal logic (Gupta, Smith, and Shalley 2006). The fact that more resources are being allocated to technological exploration implies that fewer resources are dedicated to market 
exploration and vice versa. The tendency towards exploration within one domain thus will be compensated by that within another domain.

Hypothesis 2. There is a negative relationship between exploration in the technological knowledge domain and exploration in the market knowledge domain.

\subsection{Firm-level failure experience and exploration and exploitation}

Failure refers to 'the termination of an initiative that has fallen short of its goals' (McGrath 1999, 14). Research has focused on various types of failure, such as technological failure (Schilling 1998), product failure (Cooper 1979), process failure (Shepherd, Covin, and Kuratko 2009), service failure (Zhu, Sivakumar, and Parasuraman 2004), market failure (Dundas and Richardson 1980), organisational failure (Baum and Mezias 1992) and strategic failure (Lant and Montgomery 1987). Failure is found to have impact on new business entrants (Holbrook et al. 2000), firms' risk-taking (Audia and Greve 2006; Desai 2008), inter-organisational activities (Arino and de la Torre 1998) and organisational performance (Baum and Dahlin 2007; Kim and Miner 2007). Scholars have shown the importance of learning from firm-level failure, while acknowledging that it can be 'one of the most difficult things' that an organisation does because it requires 'focused effort and attention, and the willingness to make hard choices' (Wheelwright and Clark 1992).

In this study, failure is defined as the termination of a product development initiative in a high-technology firm. This firm-level failure is associated with experiments and provides the organisation with opportunities to learn from its experience (Cannon and Edmondson 2005). However, studies that stress the importance of organisational learning have largely neglected to examine adaptive organisational learning processes as an organisation's responses to its firmlevel failure. Although scholars have examined the impact of project failure on individual learning behaviours through psychological perspectives (Shepherd 2003; Shepherd, Covin, and Kuratko 2009), little effort has been made to investigate empirically how project failure affects organisational learning in longitudinal analysis. This limitation might arise as a result of the biased sample of observations available to the organisations, which consists of the survivors from a selective process and, hence, eliminates a large number of failures (Denrell 2003). It can be counterproductive because success reduces employees' incentives to experiment (Lee and Van den Steen 2010). Success is reported to delude individuals and organisations into thinking everything is fine and believing that no correction is necessary (Sitkin 1992). Thus, an anti-failure bias may lead to the loss of important lessons in negative consequences (McGrath 1999). The under-sampling of failure has contributed to a variety of false beliefs about effective management (Denrell 2003). For instance, an individual's desire to believe in the success of the new venture has been seen to make it difficult to terminate projects that performed poorly (Royer 2003).

\subsection{Contrasting effects of failure experience on exploration and exploitation}

According to performance feedback theory (Greve 1998), performance is one of the clearest indicators of the viability of an organisation's strategy (Zajac and Kraatz 1993) because organisations are goal-directed systems that use simple decisions to adapt behaviour in response to performance feedback (Iyer and Miller 2008). Theoretical and empirical studies have supported the notion that performance feedback influenced firms' future strategy (Mezias, Chen, and Murphy 2002). An important idea taken from performance feedback theory is that risk-taking is oriented towards goals: the behaviour differs depending on whether the actor is above or below some aspiration 
level (Greve 1998). Performance has triggered organisational search because performance above or below aspirations has determined the boundary between success and failure (Fiegenbaum, Hart, and Schendel 1996; Greve 2003; Lant and Mezias 1990; Lant, Milliken, and Batra 1992). Case study research has demonstrated that performance shocks can have the effect of overcoming inertial forces resistant to exploration activities and can stimulate organisational renewal. This can occur either via exploration induced rejuvenation, or in some circumstances a rebalancing of exploration and exploitation activities in the technological and market domain resulting in long term rejuvenation (McNamara and Baden-Fuller 1999).

Failure tends to cause risk-taking behaviours and search beyond organisational routines (Greve 1998; Kahneman and Tversky 1979). Students of performance feedback theory have generally argued for a positive relationship between failure and subsequent exploration orientation. Organisations that experienced failure are deemed more likely to reorient than organisations that experienced success (Fombrun and Ginsberg 1990; Ginsberg 1988). They respond to poor performance by making a broad range of strategic and operational changes (Audia and Greve 2006; Bolton 1993; Greve 2003). Failure makes it easier for firms to overcome barriers to organisational and strategic change (Lant and Mezias 1992) because it signals that their existing strategy and activities might not meet the requirements of the changing environment and severe competition (Kiesler and Sproull 1982). A new product development initiative requires both technological knowledge and market knowledge to fulfil its function and to satisfy customer needs. The termination of the product development initiative thus implies that the technological and market knowledge does not match or fails to meet either the organisation's or the industry's standards. Hence, organisations experiencing firm-level failure may search for new solutions, which in turn lead to explorative activities.

However, since technological and market exploration triggered by failure involves risk-taking, the notion of risk aversion argues that firms tend to reinforce their routines when facing undesirable levels of uncertainty and risk. Actions that depart from the current strategy and organisational routines will have lesser-known consequences and thus will be seen as risky (Bromiley 1991; Kahneman and Tversky 1979; March and Shapira 1992). Theoretical work has proposed that the trade-off between risk-taking and risk aversion tends to be made in favour of more exploitation because exploration can only intensify the levels of risk and uncertainty (Levinthal and March 1993). Firms will show risk aversion while experiencing failure and, hence, pursue more exploitation in both domains. Acknowledging the contrasting effects of failure on subsequent exploration orientation, this study will examine two competing hypotheses.

Hypothesis 3c. There is a positive relationship between firm-level failure experience and exploration in the technological knowledge domain.

Hypothesis 3d. There is a negative relationship between firm-level failure experience and exploration in the technological knowledge domain.

Hypothesis 4e. There is a positive relationship between firm-level failure experience and exploration in the market knowledge domain.

Hypothesis 4f. There is a negative relationship between firm-level failure experience and exploration in the market knowledge domain.

Figure 1 shows the conceptual framework of this study as well as the hypothesised relationships between the constructs. 


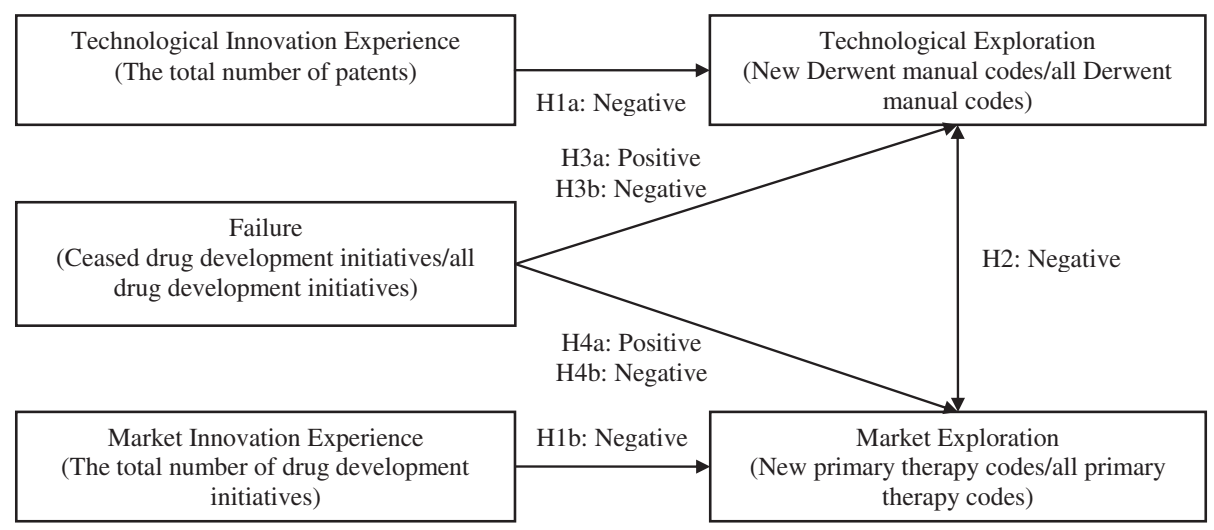

Figure 1. The theoretical framework.

\section{Methods}

\subsection{Research setting, sample and data}

This study is designed as a longitudinal analysis of drug development initiatives obtained from 191 firms in the four industry groups bearing the Standard Industrial Classification (SIC) codes 2833 (Medicinal chemicals and botanical products), 2834 (Pharmaceutical preparations), 2835 (In vitro and in vivo diagnostic substances) and 2836 (Biological products, except diagnostic substances) from 1990 to 2008 . These industry groups provide an attractive and necessary venue for this study because of the intensive knowledge exploration and exploitation they involve, which enhances the variance and reliability of the variables. Furthermore, the availability of longitudinal data on drug development initiatives is another advantage of the empirical setting. Firms in these groups are generally research- and development-intensive and their new product development represents a principal means of renewal in these firms (Dougherty 1992). The sampled firms were publicly traded, which assisted in the obtaining of financial data.

Failures are high-frequency events in the empirical setting of this study, which give this industry an advantage over others. Understanding the impact of failure is critical to the effective and efficient management of drug-development processes, which are affected by a number of factors such as fewer drug introductions and increased R\&D expenditure (Bradfield and El-Sayed 2009; Cardinal 2001; Taggart 1993). This study of failure in the bio-pharmaceutical industry is especially appealing because it draws upon a large proportion of activities that failed, involving the discovery of new knowledge and advances on existing knowledge (Cardinal and Lei 2000; Freeman 1974; Pavitt 1990). In new product development, the failure rate remains relatively stable at $59 \%$ (Thieme, Song, and Shin 2003). This rate is higher in the bio-pharmaceutical industry. Previous research shows that the average failure rate of the industry is as high as $69.8 \%$ (DiMasi and Grabowski 2007). We use the database Pharmaprojects to collect our data on clinical trial experience, both successful completion of stages of clinical trials and the failure, or termination, of clinical trials. In this dataset the overall percentage of terminated drug development initiatives is $71.5 \%$.

The four databases used in this study are Pharmaprojects, Derwent Innovations Index, Research Insight (including two sub-datasets, Compustat and Global Vantage) and PR Newswire (part of LexisNexis). Pharmaprojects provides detailed information about drug development initiatives and research and development processes. It reports the initiation, progress and termination of preclinical trials and phase one, two and three human clinical trials and also market launch information 
on the research and development activities of a large panel of public listed pharmaceutical and biotechnology firms. Derwent Innovations Index is a major source of patent data. Research Insight provides financial statement information from both active and inactive publicly traded firms. PR Newswire is a leading source of news and multimedia content from various types of organisation where the alliance announcements of the firms were collected. The 191 firms were randomly selected from 300 of the largest firms in the Pharmaprojects database as measured in terms of their numbers of drug development initiatives in 2004. The unit of analysis is the firm.

\subsection{Measures}

\section{Exploration orientation}

Exploration and exploitation are two ends of a continuum (Gupta, Smith, and Shalley 2006; Levinthal and March 1993) and hence vary in the degree to which they require new knowledge (Cardinal 2001). Thus, the measurement of exploration and exploitation in this study depends on a continuous variable, exploration orientation, that reflects the extent to which firms use knowledge that is 'new to the firm' instead of 'new to the industry' because Gupta, Tesluk, and Taylor (2007) pointed out that 'most new ideas emerge as novel recombination of old ideas, restricting the definition of innovation only to those ideas that are utterly new to the world would make this concept almost empty and devoid of any connection with ground-level reality' (Gupta, Tesluk, and Taylor 2007, 886).

Technological exploration orientation refers to the extent to which a firm uses new technology in its product development, represented by the Derwent manual codes of the patents assigned to the firm. We compared the Derwent manual codes used by a focal firm in a given year to those used by the same firm in the year prior to the given year in order to identify the number of codes that were new to the firm in the given year. The logic of this measure is consistent with that used by Katila and Ahuja (2002). They used a proportion of previously unused knowledge to a firm's knowledge base in a given year to measure the exploration of new knowledge (Katila and Ahuja 2002). The data were obtained from the Derwent Innovations Index.

Market exploration orientation focuses on the amount of new knowledge represented by therapy codes that a firm utilises in its drug development initiatives. According to the definition given by Pharmaprojects, a therapy code corresponds to a drug's therapy description, which denotes the disease area for which it is being developed. The use of therapy codes offers several advantages. First, each therapy code corresponds to a disease area, which is the potential market of a drug product. New market knowledge is therefore clearly identified by changes in the therapy codes. Second, each drug is assigned at least one of the 218 therapy codes. ${ }^{1}$ This measure is effective to capture the change in knowledge applied by a focal firm in a given year. After consulting researchers in the academic areas related to clinical trials, we conclude that market exploration orientation can be measured as changes in the therapy codes utilised by the firm. This point is further confirmed by the research conducted by Anand, Mesquita, and Vassolo (2009), where the authors interviewed industry executives, pharmacists, hospital doctors and clinicians before they concluded that 'each market represents, and is named after, a therapeutic treatment' (807) and, hence, a market referred to a therapeutic class. This raises the validity of this indicator of therapy code as market exploration orientation in this study. We compared the therapy codes used by a focal firm in a given year to those used by the same firm in the year prior to the given year to identify the number of therapy codes that were new to the firm in the given year. 
Both technological and market exploration orientations are measured as the ratio of the number of codes that are new to the firm to the number of all the codes applied by the firm in a given year. The value ranges between 0 and 1, with 0 denoting a scenario in which all the codes used by a firm in a given year existed in the previous year and 1 a scenario in which all the codes are new to the firm in the given year. Thus, 0 represents pure exploitation and 1 pure exploration. Both variables were mean-centred.

\section{Innovation experience}

Technological innovation experience captures the experience that a firm has in its technological knowledge domain, which is measured by the total number of patents assigned to the firm from 1990 to the year prior to a given year. The data were obtained from the Derwent Innovations Index. Market innovation experience, following the same logic, is measured as the total number of drugs that a firm initiated in its drug development pipeline from 1990 to the year prior to a given year. The data were collected from Pharmaprojects. Both values were log-transformed.

\section{Failure}

Failure in this study is defined as the extent to which a firm had experience in the termination of product development initiatives. It is measured as the ratio of the number of ceased drug development initiatives ${ }^{2}$ to the number of all the drug development initiatives in a focal firm in the period from 1990 to the year prior to the given year. The value of this variable ranges between 0 and 1 , with 0 denoting a scenario in which the firm did not terminate any drug development initiatives in the period prior to a given year and 1 a scenario in which all the drug development initiatives in the firm failed in the period. This measure captures a firm's overall failure experience in drug development in comparison to its research and development effort to initiate new drug development projects. It eliminates the bias caused by using the number of ceased drug development initiatives by controlling for the size of a portfolio of drug development projects. The data were collected from Pharmaprojects. The variable was mean-centred.

\section{Control variables}

(1) Resource base. The resource-based view (Barney 1991; Wernerfelt 1984) argues that firms' resources affect their competitive advantage and innovation (Galunic and Rodan 1998; King and Hegarty 2003). Prior research has examined the impact of resource constraints (Rao and Drazin 2002) and slack resources (Daniel et al. 2004) on innovation and firm performance. Following prior research (Sheppard 1994), a firm's resource base is measured as net worth over total assets. Chen and Shimerda (1981), Chudson (1945) and Pinches and Mingo (1973) suggested in their studies that net worth over total assets is an important, useful ratio to measure firms' resource base. The data were obtained from Research Insight (Compustat and Global Vantage).

(2) Firm risk. Risk-taking or risk aversion affects firms' preferences for exploration or exploitation. One of the main concerns in this study relates to organisational learning under risk caused by failure. Thus, firm risk, measured as $\beta$, is an important control variable and was utilised in prior studies (Guthrie and Datta 1997). The data were collected from Research Insight.

(3) Alliance. Alliances are reported by a number of studies to have a significant impact on innovation (e.g. Gay and Dousset (2005)). This variable is measured as the logarithmic transformation of the number of alliances a firm started in the period from 1990 to the year prior to a give year. The data were obtained from PR Newswire announcements of alliance formations where the one of the partners is a firm included in our sample. 
(4) Firm size. Firm size affects innovation (Damanpour 1992). It is measured as the logarithmic transformation of the number of employees of a firm in a previous year as reported in Research Insight.

\subsection{Analysis}

A generalised least square (GLS) fixed-effect linear regression was utilised to test the hypotheses with Stata/SE 11. Although the choice between fixed- and random-effects regression depends on the interest of researchers (Mundlak and Yahav 1981), fixed-effect regressions control for unobserved heterogeneity in the form of time-invariant variables, which are preferred to GLS random effects in this study. The results of the Hausman test (Hausman 1978) confirm that fixed-effect regressions should be adopted. The effective sample size and, hence, the number of observations vary for a number of reasons. First, data obtained from the data sources do not cover the same period from 1990 to 2008 . For some firms, for example, data are available for the period from 1995 to 2006 . Second, the minimum number of observations per firm required for measuring the exploration orientation variables is two. Missing observations were processed using a pairwise deletion procedure. The control variables were winsorised with Stata/SE 11. The winsorised fraction was 0.025 .

Table 1 presents descriptive statistic and pairwise correlations among the variables. Table 2 reports the results of the analysis of the panel data with fixed-effect models and generalised least square (GLS) regressions.

\section{Results}

Hypothesis 1a predicts a negative relationship between innovation experience and exploration in the technological knowledge domain in the high-technology firms. Model 2a reports a negative and significant coefficient in the technological knowledge domain. Hypothesis 1a is thus supported, which suggests a reinforcing tendency for imbalance between exploration and exploitation within the domain. The effect holds when controlling for exploration orientation in the market knowledge domain, shown in Model 4a. Similarly, Hypothesis 1b obtains a significant coefficient in the market knowledge domain, supporting a negative relationship between innovation experience and exploration in the market knowledge domain. The results are shown in Model $2 \mathrm{~b}$. The effect holds when controlling for exploration orientation in the technological knowledge domain, shown in Model 4b.

In support of Hypothesis 2, which predicts a negative relationship between technological exploration orientation and market exploration orientation, Models $3 \mathrm{a}$ and $3 \mathrm{~b}$ reveal a negative association between technological exploration orientation and market exploration orientation. This finding suggests that firms that concentrated on technological exploration such as patenting activities tended to favour initiating fewer new drug development projects, whilst, firms focusing on market exploration would prefer lower levels of uncertainty in the technological knowledge domain. The effect holds when controlling for innovation experience within domains, shown in Model 4a and 4b.

Hypothesis 3 and 4 examine the contrasting effects of failure experience on exploration orientation. In keeping with Hypothesis $3 \mathrm{a}$ instead of its competing counterpart Hypothesis $3 \mathrm{~b}$ in the technological knowledge domain, the positive association between failure and technological exploration orientation reveals that firms in the sample tended to be risk-seeking if they experienced failed drug development projects. The effect holds when controlling for technological 
Table 1. Descriptive statistics and pairwise correlations.

\begin{tabular}{|c|c|c|c|c|c|c|c|c|c|c|c|c|}
\hline & & Variable & Mean & Std. Dev. & 1 & 2 & 3 & 4 & 5 & 6 & 7 & 8 \\
\hline DV & 2 & Market exploration orientation & 0.00 & 0.28 & $0.07 *$ & 1.00 & & & & & & \\
\hline \multirow{2}{*}{ IV } & 4 & Market innovation experience & 1.10 & 0.64 & 0.03 & -0.01 & $-0.05 *$ & 1.00 & & & & \\
\hline & 5 & Failure & 0.00 & 0.13 & 0.02 & $0.06 *$ & 0.02 & -0.03 & 1.00 & & & \\
\hline \multirow[t]{2}{*}{$\mathrm{CV}$} & 6 & Resource base & 0.62 & 0.34 & 0.01 & $0.07 *$ & 0.02 & $0.17 *$ & $0.34 *$ & 1.00 & & \\
\hline & 7 & Firm risk & 1.32 & 1.05 & 0.02 & 0.01 & -0.04 & 0.03 & -0.03 & -0.02 & 1.00 & \\
\hline
\end{tabular}

Significance levels: ${ }^{*} p<0.05$. 
Table 2. Exploration orientation within and across domains and the impact of failure

\begin{tabular}{|c|c|c|c|c|c|c|c|c|c|}
\hline DV & & \multicolumn{4}{|c|}{ Technological exploration orientation } & \multicolumn{4}{|c|}{ Market exploration orientation } \\
\hline \multicolumn{10}{|l|}{ Independent variables } \\
\hline \multirow[t]{2}{*}{ 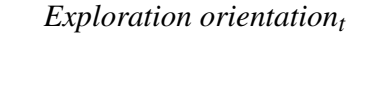 } & Technological & & & & & & -0.10 & $0.14 \dagger$ & $-0.13 \dagger$ \\
\hline & Market & & & $-0.04 \dagger$ & $-0.03 \dagger$ & & & & \\
\hline \multirow{2}{*}{ Control variables } & Alliance $_{t-1}$ & 0.04 & $0.04 \dagger$ & 0.03 & $0.05 \dagger$ & $0.12 * *$ & $0.15^{* *}$ & $0.12 \dagger$ & $0.11 *$ \\
\hline & Firm Size $_{t-1}$ & $-0.03 \dagger$ & $-0.03 \dagger$ & -0.01 & -0.02 & $-0.06 \dagger$ & $-0.08 *$ & -0.03 & -0.03 \\
\hline Intercept & & $-0.07 \dagger$ & $0.32 * *$ & $-0.08 *$ & $0.30 *$ & $-0.09 \dagger$ & 0.19 & $-0.15^{*}$ & 0.15 \\
\hline \multirow[t]{3}{*}{$R^{2}$} & within & 0.05 & 0.06 & 0.06 & 0.08 & 0.08 & 0.07 & 0.08 & 0.12 \\
\hline & between & 0.00 & 0.01 & 0.01 & 0.02 & 0.01 & 0.01 & 0.01 & 0.00 \\
\hline & overall & 0.01 & 0.02 & 0.02 & 0.01 & 0.04 & 0.03 & 0.05 & 0.02 \\
\hline$F$ & & $3.47 * *$ & $5.85 * *$ & $3.84 * *$ & $4.83 * *$ & $5.73 * *$ & $5.58 * *$ & $4.96^{* *}$ & $4.88 * *$ \\
\hline
\end{tabular}

Significance levels: $\dagger p<0.10 ;{ }^{*} p<0.05 ; * * p<0.01$. 
innovation experience and market exploration orientation. However, in the market knowledge domain, there is no significant relationship between firm-level failure and market exploration orientation, though all the coefficients have negative signs. The findings reveal that failure alone is not sufficient to explain the tendencies for exploration in the market knowledge domain.

With respect to the control variables, the results suggest that firms' resource base is positively related to technological exploration orientation in three out of the four models. Firm risk is positively associated with market exploration orientation but not technological exploration orientation. Alliances positively affect exploration orientation in the market knowledge domains, but the effect holds in the technological knowledge domain only when technological innovation experience is controlled. Firm size has a negative impact on exploration orientation within each domain.

\section{Discussion}

\subsection{Conclusion}

Anchored in the exploration and exploitation literature, this study provides evidence of the imbalance between exploration and exploitation within intra-organisational domains by advancing our knowledge of domain separation of exploration and exploitation in the internal context of a firm's new product development. Firms follow a self-reinforcing tendency within intra-organisational domains and balance exploration and exploitation across the domains over time. This study further demonstrates that firms in the sample tended to pursue technological exploration rather than market exploration if they experienced project development failure. The results of the hypotheses are illustrated in Figure 2.

\subsection{Contributions}

This study contributes to the exploration and exploitation literature in several ways. First, complementing existing research on exploration and exploitation (Gibson and Birkinshaw 2004; He and Wong 2004) which argues that organisations should balance exploration and exploitation within organisational domains, this work supports the perspective that firms can on balancing exploration and exploitation across domains (Lavie and Rosenkopf 2006). It thus provides a dynamic view

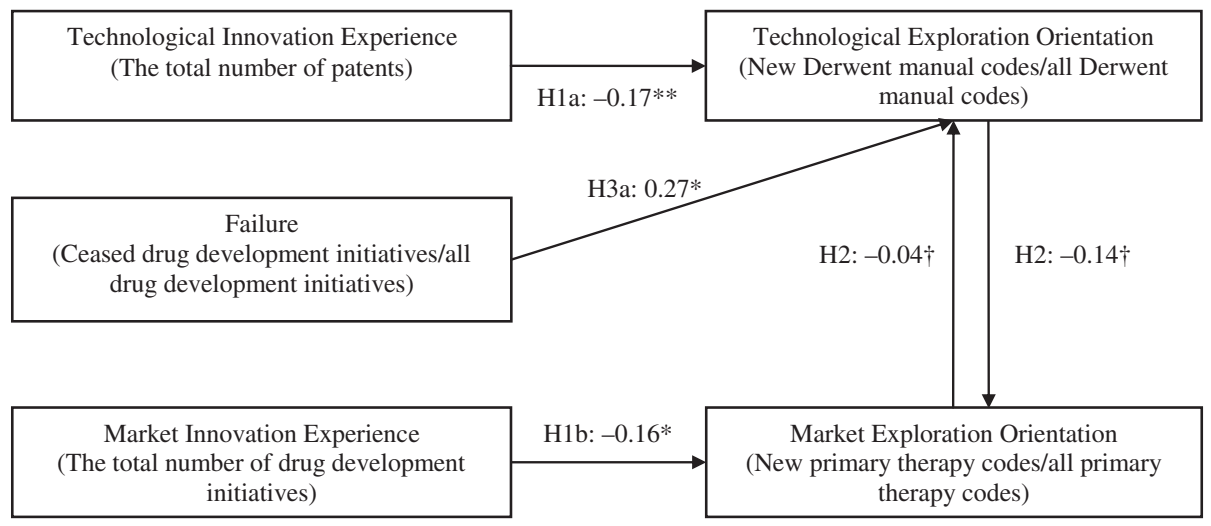

Significance levels: $\dagger p<0.10, * p<0.05, * * p<0.01$.

Figure 2. The results: exploration orientation within and across domains and the impact of failure. 
on balancing exploration and exploitation in an intra-organisational context, parallel to that in an inter-organisational context. The self-reinforcing manner of exploration and exploitation remains in the intra-organisational context. Therefore, the results of this study will intensify the debate on the balance between exploration and exploitation by providing evidence that trade-offs may not be practically preferred by the firms within their particular domains. In support of March (1991), this study demonstrates that firms act as dynamic systems and may pursue organisational separation (He and Wong 2004) and temporal separation (Tushman and Anderson 1986) through domain separation (Lavie and Rosenkopf 2006). A firm may emphasise either exploration or exploitation within a single domain at a time but pursue a balance across several domains. This study highlights the possibility of easing tension between exploration and exploitation within the firm.

Second, this study extends the domain separation approach of exploration and exploitation into the internal context of an organisation by identifying and developing two domains, the technological knowledge domain and the market knowledge domain, in the firm's new product development environment. The identification of new domains facilitates the development and utilisation of the domain separation approach (Lavie, Stettner, and Tushman 2010). The two domains established in this study follow the logic provided by (Lavie and Rosenkopf 2006) and thus capture the key features of the information contained in each domain. This step contributes to future empirical research on examining domain separation as a balancing mode of exploration and exploitation at various levels and in various industries.

Third, adopting performance feedback theory, this paper empirically tests the notion of the failure trap (Levinthal and March 1993) by demonstrating how firm-level failure, which is associated closely with performance below aspirations, triggers technological search beyond a firm's knowledge base. The existing research fell short of furnishing empirical evidence for the failure trap. The current study suggests that failure leads to exploration in technological knowledge domain, which leads to more failure; this, in turn, leads to more exploration (Levinthal and March 1993).

Fourth, this work enriches empirical research on domain separation through longitudinal analysis. Review articles (e.g. Raisch and Birkinshaw (2008)) in this stream of literature reveal that longitudinal analysis is scarce compared to cross-sectional analysis. In the special issue on ambidexterity in Organisation Science (Raisch et al. 2009), two out of seven articles are longitudinal analyses. In their review of organisational ambidexterity (Simsek et al. 2009), the authors identified three longitudinal studies out of 29 influential articles in the field. Articles based on survey analysis and field study seem to be in a majority. This influences generalisations of and comparisons between the findings (Lavie, Stettner, and Tushman 2010). The present study significantly contributes to the field by its empirical operationalisation and the significant findings of the longitudinal analysis.

\subsection{Implications}

The tendency to balance exploration and exploitation within and across intra-organisational domains parallels that within and across inter-organisational domains (Lavie and Rosenkopf 2006), though empirical studies on the domain separation of exploration and exploitation are limited in number. Identifying the domains where exploration and exploitation occur is of great importance because the proper identification of domains helps scholars to draw consistent conclusions given that equivalent interpretations are possible per domain (Lavie, Stettner, and Tushman 2010). Future studies are encouraged to examine the exploration and exploitation orientations within and across various domains of the internal or external context of an organisation. The self-reinforcing trend in each domain is expected to obtain. Practically, managers may not expect 
equal amounts of exploration and exploitation within the domains of a firm (Cao, Gedajlovic, and Zhang 2009) because the overall balance may be reached across intra-organisational domains or even inter-organisational domains (Lavie and Rosenkopf 2006) over time.

The second implication of this study is that it is possible to transfer one mode of balancing exploration and exploitation to another and, hence, to release the tensions between various approaches to balancing the two. This research shows that market knowledge as a separate domain from technological knowledge can enjoy exploration and exploitation that is interdependent from that in the technological knowledge domain. The organisational separation approach (He and Wong 2004; Jansen et al. 2009; Tushman and O'Reilly 1996), commonly conceives of exploration as technological research and development activities and exploitation as marketing-related activities (Voss, Sirdeshmukh, and Voss 2008). The results of this generally demonstrate that the two compete with each other for scarce resources. The findings in this study, based on domain separation, are consistent with the findings which emerge from the organisational separation approach.

Third, an important implication of this study relates to the top management teams that endeavour to manage failure in the innovation processes of high-technology firms. Managers should fully acknowledge the impact of firm-level failure on the search behaviours of the organisations and on their future development. In the pharmaceutical industry, the high failure rate of clinical trials represents a serious economic burden for the companies. The increasing cost of drug development has largely decreased companies' competitive advantage and thus stimulated a revolution in the drug discovery sector (Amir-Aslani and Mangematin 2010). Failure experience also affects firms' efficiency in its operations and innovation processes, which are associated with their innovation performance and organisational growth (Alegre, Chiva, and Lapiedra 2009). Therefore, future research might examine the impact of failure experience on innovation and organisational performance in high-technology firms may enable firms to capture or create potential economic value by learning from failure experience.

\subsection{Limitations}

Future research could address some of the limitations of this study. First, future research is encouraged to identify other domains of the internal context of an organisation and to examine the exploration and exploitation orientations within and across various domains. Second, the relationship between failure and market exploration might warrant a detailed examination in future research. Whether the results would be sensitive to the identification of a domain has yet to be identified. Third, future research might investigate the performance implication of the balance between exploration and exploitation within and across intra-organisational domains as well as how the interaction between exploration/exploitation and failure might affect organisational performance. Lavie, Kang, and Rosenkopf (2009) examined the performance implication of balancing exploration and exploitation within and across inter-organisational domains in alliance formation. They found that balance undermined organisational performance and specialisation improved it. It would be interesting to empirically explore whether or not these findings of Lavie, Kang, and Rosenkopf (2009) are replicated using R\&D project level data measuring intra and inter-organizational domains of knowledge exploration and exploitation in the presence of both success and failure experience. Fourth, future research might test the domain separation approach of exploration and exploitation in various industries. This is because some variables are particularly rooted in the pharmaceutical industry, such as technological exploration orientation and market exploration orientation. Furthermore, patent data may be an effective indicator of exploration in high-technology industries. Future research might develop measures appropriate 
for other industries of interest. Fifth, this study does not find a significant relationship between failure experience and market exploration. Various factors could affect market exploration, such as industrial regulations (Phillips et al. 2011). Since this study focuses on the internal clinical trials of the firms in the sample, it is not able to identify industrial factors that might affect its dependent variables, which could be addressed by future research.

\section{Acknowledgements}

We gratefully acknowledge the feedback and insights provided by Thomas Allen, Ciaran Heavey, Brian McGrath, Dorota Piaskowska, Lourdes Sosa, participants at the Innovation General Track of EURAM 2011 annual conference and our anonymous reviewers. We especially acknowledge the financial support from the Irish Government's Programme for Research in Third Level Institutions (PRTLI 5) project grant entitled 'Innovation Policy Simulation for the Smart Economy (IPSE)'. Peiran Su extends his thanks to UCD Ad Astra Research Scholarship fund for supporting his doctoral research.

\section{Notes}

1. Therapy codes are grouped under Anatomical Therapeutic Chemical (ATC) Drug Classification System (WHO 2003).

2. There are three statuses of a drug development initiative, namely, ceased, active and fully launched. All the ceased drug development initiatives are considered as failures in this study because the ceased dataset contains those drugs whose development has been completely discontinued by the company concerned and those withdrawn from the market after launch, according to Pharmaprojects. A drug development initiative in pharmaceutical companies begins with the discovery of a molecule based on a combination of new and existing knowledge. It is followed by six stages: pre-clinical trial, Phase 0, Phase I, Phase II, Phase III and Phase IV clinical trials (Food and Drug Administration (FDA) 2006). The results of these trials are submitted to regulatory authorities before the drug can be commercialised and reach the market (Pisano 1994). Failure can occur at any of the six stages before the final approval by an authority.

\section{Notes on contributors}

Peiran Su is a researcher at the Michael Smurfit School of Business, University College Dublin. He is completing his PhD in strategy/general management at University College Dublin. His research focuses on creating and capturing economic value from firm level innovation and how project failure impacts upon both project and firm level performance.

Peter McNamara is a senior lecturer at the Michael Smurfit School of Business, University College Dublin, where he is also the Director of both the $\mathrm{PhD}$ programme and the MSc Business. His research explores the relationship between project failure and success and firm performance; the antecedents and performance consequences of star talent; and the process of generating and sustaining cooperation in diverse stakeholder networks and his main empirical settings pharmaceuticals, sports and education. He has published in journals such as Research Policy, Journal of Business Venturing and British Journal of Management.

\section{References}

Alegre, J., R. Chiva, and R. Lapiedra. 2009. Measuring innovation in long product development cycle industries: An insight in biotechnology. Technology Analysis \& Strategic Management 21, no. 4: 535-46.

Amir-Aslani, A., and V. Mangematin. 2010. The future of drug discovery and development: Shifting emphasis towards personalized medicine. Technological Forecasting and Social Change 77, no. 2: 203-17.

Anand, J., L.F. Mesquita, and R.S. Vassolo. 2009. The dynamics of multimarket competition in exploration and exploitation activities. Academy of Management Journal 52, no. 4: 802-21.

Arino, A., and J. de la Torre. 1998. Learning from failure: Towards an evolutionary model of collaborative ventures. Organization Science 9, no. 3: 306-25.

Audia, P.G., and H.R. Greve. 2006. Less likely to fail: Low performance, firm size, and factory expansion in the shipbuilding industry. Management Science 52, no. 1: 83-94.

Barney, J. 1991. Firm resources and sustained competitive advantage. Journal of Management 17, no. 1: 99-120. 
Baum, J.A.C., and K.B. Dahlin. 2007. Aspiration performance and railroads' patterns of learning from train wrecks and crashes. Organization Science 18, no. 3: 368-85.

Baum, J.A.C., and S.J. Mezias. 1992. Localized competition and organizational failure in the Manhattan hotel industry, 1898-1990. Administrative Science Quarterly 37, no. 4: 580-604.

Beckman, C.M. 2006. The influence of founding team company affiliations on firm behavior. Academy of Management Journal 49, no. 4: 741-58.

Benner, M.J. 2002. Process management and technological innovation: A longitudinal study of the photography and paint industries. Administrative Science Quarterly 47, no. 4: 676-706.

Bolton, M.K. 1993. Organizational innovation and substandard performance - when is necessity the mother of innovation. Organization Science 4, no. 1: 57-75.

Bradfield, R., and El-Sayed, H. 2009. Four scenarios for the future of the pharmaceutical industry. Technology Analysis \& Strategic Management 21, no. 2: 195-212.

Bromiley, P. 1991. Testing a causal model of corporate risk-taking and performance. Academy of Management Journal 34, no. 1: 37-59.

Cannon, M.D., and A.C. Edmondson. 2005. Failing to learn and learning to fail (intelligently): How great organizations put failure to work to innovate and improve. Long Range Planning 38, no. 3: 299-319.

Cao, Q., E. Gedajlovic, and H.P. Zhang. 2009. Unpacking organizational ambidexterity: Dimensions, contingencies, and synergistic effects. Organization Science 20, no. 4: 781-96.

Cardinal, L.B. 2001. Technological innovation in the pharmaceutical industry: The use of organizational control in managing research and development. Organization Science 12, no. 1: 19-36.

Cardinal, L.B., and D. Lei. 2000. Structuring research and development teams in the technological conversion process. In Advances in interdisciplinary studies of work teams, ed. M.M. Beyerlein, D.A. Johnson and S.T. Beyerlein, 31-62. Greenwich, CT: JAI Press.

Chen, K.H., and T.A. Shimerda. 1981. An empirical-analysis of useful financial ratios. Financial Management 10, no. 1: 51-60.

Chudson, W.A. 1945. The pattern of corporate financial structure. New York: National Bureau of Economic Research.

Cohen, W.M., and D.A. Levinthal. 1990. Absorptive-capacity - a new perspective on learning and innovation. Administrative Science Quarterly 35, no. 1: 128-52.

Cooper, R.G. 1979. Dimensions of industrial new product success and failure. Journal of Marketing 43: 93-103.

Cyert, R.M., and J.G. March. 1963. A behavioural theory of the firm. Englewood Cliffs, NJ: Prentice-Hall.

Damanpour, F. 1992. Organizational size and innovation. Organization Studies 13, no. 3: 375-402.

Daniel, F., F.T. Lohrke, C.J. Fornaciari, and R.A. Turner. 2004. Slack resources and firm performance: A meta-analysis. Journal of Business Research 57, no. 6: 565-74.

Danneels, E. 2002. The dynamics of product innovation and firm competences. Strategic Management Journal 23, no. 12: $1095-121$.

Denrell, J. 2003. Vicarious learning, undersampling of failure, and the myths of management. Organization Science 14, no. 3: 227-43.

Desai, V.M. 2008. Constrained growth: How experience, legitimacy, and age influence risk taking in organizations. Organization Science 19, no. 4: 594-608.

DiMasi, J.A., and H.G. Grabowski. 2007. The cost of biopharmaceutical R\&D: Is biotech different? Managerial \& Decision Economics 28, no. 4/5: 469-79.

Dougherty, D. 1992. A practice-centered model of organizational renewal through product innovation. Strategic Management Journal 13: 77-92.

Dundas, K.N.M., and P.R. Richardson. 1980. Corporate-strategy and the concept of market failure. Strategic Management Journal 1, no. 2: 177-88.

FDA. 2006. Guidance for industry, investigators, and reviewers - exploratory IND studies. U.S. Department of Health and Human Services Food and Drug Administration Center for Drug Evaluation and Research (CDER). http://www.fda.gov/downloads/Drugs/GuidanceComplianceRegulatoryInformation/Guidances/UCM078933.pdf (accessed January 2006).

Fiegenbaum, A., S. Hart, and D. Schendel. 1996. Strategic reference point theory. Strategic Management Journal 17, no. 3: $219-35$.

Fombrun, C.J., and A. Ginsberg. 1990. Shifting gears - enabling change in corporate aggressiveness. Strategic Management Journal 11, no. 4: 297-308.

Freeman, C. 1974. The economics of industrial innovation. Harmondsworth, UK: Penguin.

Galunic, D.C., and S. Rodan. 1998. Resource recombinations in the firm: Knowledge structures and the potential for Schumpeterian innovation. Strategic Management Journal 19, no. 12: 1193-201. 
Gay, B., and B. Dousset. 2005. Innovation and network structural dynamics: Study of the alliance network of a major sector of the biotechnology industry. Research Policy 34, no. 10: 1457-75.

Gibson, C.B., and J. Birkinshaw. 2004. The antecedents, consequences, and mediating role of organizational ambidexterity. Academy of Management Journal 47, no. 2: 209-26.

Ginsberg, A. 1988. Measuring and modeling changes in strategy - theoretical foundations and empirical directions. Strategic Management Journal 9, no. 6: 559-75.

Greve, H.R. 1998. Performance, aspirations, and risky organizational change. Administrative Science Quarterly 43, no. 1: 58-86.

Greve, H.R. 2003. A behavioral theory of R\&D expenditures and innovations: Evidence from shipbuilding. Academy of Management Journal 46, no. 6: 685-702.

Gupta, A.K., S.P. Raj, and D. Wilemon. 1986. A model for studying research-and-development - marketing interface in the product innovation process. Journal of Marketing 50, no. 2: 7-17.

Gupta, A.K., K.G. Smith, and C.E. Shalley. 2006. The interplay between exploration and exploitation. Academy of Management Journal 49, no. 4: 693-706.

Gupta, A.K., P.E. Tesluk, and M.S. Taylor. 2007. Innovation at and across multiple levels of analysis. Organization Science 18, no. 6: 885-97.

Guthrie, J.P., and D.K. Datta. 1997. Contextual influences on executive selection: Firm characteristics and CEO experience. Journal of Management Studies 34, no. 4: 537-60.

Hannan, M.T., and J. Freeman. 1984. Structural inertia and organizational-change. American Sociological Review 49, no. 2: 149-64.

Hausman, J.A. 1978. Specification tests in econometrics. Econometrica 46, no. 6: 1251-71.

He, Z.L., and P.K. Wong. 2004. Exploration vs. exploitation: An empirical test of the ambidexterity hypothesis. Organization Science 15, no. 4: 481-94.

Helfat, C.E., and M.A. Peteraf. 2003. The dynamic resource-based view: Capability lifecycles. Strategic Management Journal 24, no. 10: 997-1010.

Holbrook, D., W.M. Cohen, D.A. Hounshell, and S. Klepper. 2000. The nature, sources, and consequences of firm differences in the early history of the semiconductor industry. Strategic Management Journal 21, no. 10-11: $1017-41$.

Homsma, G.J., C. van Dyck, D. de Gilder, P.L. Koopman, and T. Elfring. 2009. Learning from error: The influence of error incident characteristics. Journal of Business Research 62, no. 1: 115-22.

Iyer, D.N., and K.D. Miller. 2008. Performance feedback, slack, and the timing of acquisitions. Academy of Management Journal 51, no. 4: 808-22.

Jansen, J.J.P., M.P. Tempelaar, F.A.J. van den Bosch, and H.W. Volberda. 2009. Structural differentiation and ambidexterity: The mediating role of integration mechanisms. Organization Science 20, no. 4: 797-811.

Kahneman, D., and A. Tversky. 1979. Prospect theory - analysis of decision under risk. Econometrica 47, no. 2: $263-91$.

Katila, R., and G. Ahuja. 2002. Something old, something new: A longitudinal study of search behavior and new product introduction. Academy of Management Journal 45, no. 6: 1183-94.

Kiesler, S., and L. Sproull. 1982. Managerial response to changing environments - perspectives on problem sensing from social cognition. Administrative Science Quarterly 27, no. 4: 548-70.

Kim, J.Y., and A.S. Miner. 2007. Vicarious learning from the failures and near-failures of others: Evidence from the US commercial banking industry. Academy of Management Journal 50, no. 3: 687-714.

King, D.R., and W.H. Hegarty. 2003. Complementary resources and the exploitation of technological innovations. Journal of Management 29, no. 4: 589-606.

Kogut, B., and U. Zander. 1992. Knowledge of the firm, combinative capabilities, and the replication of technology. Organization Science 3, no. 3: 383-97.

Lant, T.K., and S.J. Mezias. 1990. Managing discontinuous change - a simulation study of organizational learning and entrepreneurship. Strategic Management Journal 11: 147-79.

Lant, T.K., and S.J. Mezias. 1992. An organizational learning-model of convergence and reorientation. Organization Science 3, no. 1: 47-71.

Lant, T.K., F.J. Milliken, and B. Batra. 1992. The role of managerial learning and interpretation in strategic persistence and reorientation - an empirical exploration. Strategic Management Journal 13, no. 8: 585-608.

Lant, T.K., and D.B. Montgomery. 1987. Learning from strategic success and failure. Journal of Business Research 15, no. 6: 503-17.

Lavie, D., J. Kang, and L. Rosenkopf. 2009. Balance within and across domains: The performance implications of exploration and exploitation in alliances. In Academy of Management Best Paper Proceedings. Chicago, IL: Academy of Management. 
Lavie, D., and L. Rosenkopf. 2006. Balancing exploration and exploitation in alliance formation. Academy of Management Journal 49, no. 4: 797-818.

Lavie, D., U. Stettner, and M.L. Tushman. 2010. Exploration and exploitation within and across organizations. Academy of Management Annals 4: 109-55.

Lee, D., and E. van den Steen. 2010. Managing know-how. Management Science 56, no. 2: 270-85.

Levinthal, D., and J.G. March. 1981. A model of adaptive organizational search. Journal of Economic Behavior \& Organization 2, no. 4: 307-33.

Levinthal, D.A., and J.G. March. 1993. The myopia of learning. Strategic Management Journal 14: $95-112$.

Li, T., and R.J. Calantone. 1998. The impact of market knowledge competence on new product advantage: Conceptualization and empirical examination. Journal of Marketing 62, no. 4: 13-29.

Lichtenthaler, U. 2009. Absorptive capacity, environmental turbulence, and the complementarity of organizational learning processes. Academy of Management Journal 52, no. 4: 822-46.

March, J.G. 1991. Exploration and exploitation in organizational learning. Organization Science 2, no. 1: 71-87.

March, J.G., and Z. Shapira. 1992. Variable risk preferences and the focus of attention. Psychological Review 99, no. 1: 172-83.

McGrath, R.G. 1999. Falling forward: Real options reasoning and entrepreneurial failure. Academy of Management Review 24, no. 1: 13-30.

McNamara, P., and C. Baden-Fuller. 1999. Lessons from the Celltech case: Balancing knowledge exploration and exploitation in organisational renewal. British Journal of Management 10: 291-301.

McPherson, M., L. Smith-Lovin, and J.M. Cook. 2001. Birds of a feather: Homophily in social networks. Annual Review of Sociology 27: 415-44.

Mezias, S.J., Y.R. Chen, and P.R. Murphy. 2002. Aspiration-level adaptation in an American financial services organization: A field study. Management Science 48, no. 10: 1285-300.

Minniti, M., and W. Bygrave. 2001. A dynamic model of entrepreneurial learning. Entrepreneurship: Theory \& Practice 25, no. 3: 5-16.

Mundlak, Y., and J.A. Yahav. 1981. Random effects, fixed effects, convolution, and separation. Econometrica 49, no. 6: $1399-416$.

Nonaka, I., and H. Takeuchi. 1995. The knowledge-creating company: How Japanese companies create the dynamics of innovation. Oxford: Oxford University Press.

Nonaka, I., and R. Toyama. 2007. Strategic management as distributed practical wisdom (phronesis). Industrial and Corporate Change 16, no. 3: 371-94.

Pavitt, K. 1990. What we know about the strategic management of technology. California Management Review 32, no. 3: 17-26.

Phillips, W., T. Johnsen, N. Caldwell, and J.B. Chaudhuri. 2011. The difficulties of supplying new technologies into highly regulated markets: The case of tissue engineering. Technology Analysis \& Strategic Management 23, no. 3: 213-26.

Pinches, G.E., and K.A. Mingo. 1973. Multivariate analysis of industrial bond ratings. Journal of Finance 28, no. 1: 1-18.

Pisano, G.P. 1994. Knowledge, integration, and the locus of learning: An empirical-analysis of process-development. Strategic Management Journal 15: 85-100.

Raisch, S., and J. Birkinshaw. 2008. Organizational ambidexterity: Antecedents, outcomes, and moderators. Journal of Management 34, no. 3: 375-409.

Raisch, S., J. Birkinshaw, G. Probst, and M.L. Tushman. 2009. Organizational ambidexterity: Balancing exploitation and exploration for sustained performance. Organization Science 20, no. 4: 685-95.

Rao, H., and R. Drazin. 2002. Overcoming resource constraints on product innovation by recruiting talent from rivals: A study of the mutual fund industry, 1986-94. Academy of Management Journal 45, no. 3: 491-507.

Rosenkopf, L., and A. Nerkar. 2001. Beyond local search: Boundary-spanning, exploration, and impact in the optical disk industry. Strategic Management Journal 22, no. 4: 287-306.

Royer, I. 2003. Why bad projects are so hard to kill. Harvard Business Review 81, no. 2: 48-56.

Schilling, M.A. 1998. Technological lockout: An integrative model of the economic and strategic factors driving technology success and failure. Academy of Management Review 23, no. 2: 267-84.

Shane, S. 2000. Prior knowledge and the discovery of entrepreneurial opportunities. Organization Science 11, no. 4: 448-69.

Shepherd, D.A. 2003. Learning from business failure: Propositions of grief recovery for the self-employed. Academy of Management Review 28, no. 2: 318-28.

Shepherd, D.A., J.G. Covin, and D.F. Kuratko. 2009. Project failure from corporate entrepreneurship: Managing the grief process. Journal of Business Venturing 24, no. 6: 588-600. 
Sheppard, J.P. 1994. Strategy and bankruptcy - an exploration into organizational death. Journal of Management 20, no. 4: 795-833.

Simsek, Z., C. Heavey, J.F. Veiga, and D. Souder. 2009. A typology for aligning organizational ambidexterity's conceptualizations, antecedents, and outcomes. Journal of Management Studies 46, no. 5: 864-94.

Sitkin, S.B. 1992. Learning through failure - the strategy of small losses. Research in Organizational Behavior 14: 231-66.

Song, M., C. Droge, S. Hanvanich, and R. Calantone. 2005. Marketing and technology resource complementarity: An analysis of their interaction effect in two environmental contexts. Strategic Management Journal 26, no. 3: 259-76.

Song, X.M., and B. Dyer. 1995. Innovation strategy and the R-and-D-marketing interface in Japanese firms - a contingency perspective. IEEE Transactions on Engineering Management 42, no. 4: 360-71.

Song, X.M., and M.E. Parry. 1997. The determinants of Japanese new product successes. Journal of Marketing Research 34, no. 1: 64-76.

Taggart, J. 1993. The world pharmaceutical industry. London: Routledge.

Taylor, A., and H.R. Greve. 2006. Superman or the fantastic four? Knowledge combination and experience in innovative teams. Academy of Management Journal 49, no. 4: 723-40.

Teece, D.J. 2007. Explicating dynamic capabilities: The nature and microfoundations of (sustainable) enterprise performance. Strategic Management Journal 28, no. 13: 1319-50.

Thieme, R.J., M. Song, and G.C. Shin. 2003. Project management characteristics and new product survival. Journal of Product Innovation Management 20, no. 2: 104-19.

Tsai, W.P. 2001. Knowledge transfer in intraorganizational networks: Effects of network position and absorptive capacity on business unit innovation and performance. Academy of Management Journal 44, no. 5: 996-1004.

Tushman, M.L., and P. Anderson. 1986. Technological discontinuities and organizational environments. Administrative Science Quarterly 31, no. 3: 439-65.

Tushman, M.L., and W.L. Moore. 1982. Readings in the management of innovation. Boston, MA: Pitman.

Tushman, M.L., and C.A. O'reilly. 1996. Ambidextrous organizations: Managing evolutionary and revolutionary change. California Management Review 38, no. 4: 8-30.

Van den Bosch, F.A.J., H.W. Volberda, and M. de Boer. 1999. Coevolution of firm absorptive capacity and knowledge environment: Organizational forms and combinative capabilities. Organization Science 10, no. 5: 551-68.

Vassolo, R.S., J. Anand, and T.B. Folta. 2004. Non-additivity in portfolios of exploration activities: A real options-based analysis of equity alliances in biotechnology. Strategic Management Journal 25, no. 11: 1045-61.

Vermeulen, F., and H. Barkema. 2001. Learning through acquisitions. Academy of Management Journal 44, no. 3: 457-76.

Voss, G.B., D. Sirdeshmukh, and Z.G. Voss. 2008. The effects of slack resources and environmental threat on product exploration and exploitation. Academy of Management Journal 51, no. 1: 147-64.

Wernerfelt, B. 1984. A resource-based view of the firm. Strategic Management Journal 5: 171-80.

Wheelwright, S.C., and K.B. Clark. 1992. Revolutionizing product development: Quantum leaps in speed, efficiency, and quality. New York: The Free Press.

WHO. 2003. Introduction to drug utilization research. World Health Organization. http://apps.who.int/medicinedocs/en/ $\mathrm{d} / \mathrm{Js} 4876 \mathrm{e} /$.

Zajac, E.J., and M.S. Kraatz. 1993. A diametric forces model of strategic change - assessing the antecedents and consequences of restructuring in the higher-education industry. Strategic Management Journal 14: 83-102.

Zhu, Z., K. Sivakumar, and A. Parasuraman. 2004. A mathematical model of service failure and recovery strategies. Decision Sciences 35, no. 3: 493-525. 